\title{
Effects of minor drainage networks on flood hazard evaluation
}

\author{
ALESSIO DOMENEGHETTI \\ School of Civil, Chemical, Environmental and Materials Engineering, DICAM, University of Bologna, Bologna, Italy \\ alessio.domeneghetti@unibo.it
}

\begin{abstract}
Scientific literature reports a plethora of numerical tools of different complexity (e.g. 1D, 2D rasterbased or full 2D models) for flood hazard and flood risk evaluation. The correct identification of the appropriate model still represents a key aspect in the overall flood hazard process even though the potential of these modelling instruments are increased by the availability of high computational resources and by the amount of high-resolution topographic data provided by recent survey techniques. Given this context the present analysis investigates the effects of minor drainage networks on the estimation of flood hazard in a flood-prone area along the Enza River, close to the village of Sorbolo a Levante (RE, northern Italy). By means of a full 2D hydraulic model (Telemac-2D), the effects of the drainage system is analysed using three unstructured meshes with different degrees of complexity: (1) the minor drainage system allows the possibility to convey water outside the study area (REF); (2) the drainage system is reproduced only in terms of preferential flow-paths (REF-noFlow); (3) the drainage network is completely neglected (REF-noDN). The analysis indicates that the maximum flood extent seems not to be influenced by the mesh schematization, while water depths and the total volume are significantly related to the model schematization. Even if this analysis refers to a specific case study and further investigations are needed, it shows the fundamental role of the drainage network in controlling water depth distribution and the duration of the inundation, which should be accurately reproduced by numerical models.
\end{abstract}

Key words minor drainage network; mesh resolution; 2D model; River Enza

\section{INTRODUCTION}

During recent decades much effort has been dedicated to the evaluation and mitigation of flood hazard and flood risk. Nevertheless, flood damages are continuously growing and flooding is one of the most costly event types in terms of loss of human lives and economic damages (e.g. EM-DAT 2011). The European Floods Directive 2007/60/EC (EC 2007) has further stimulated the development of different approaches for the evaluation of possible flood scenarios and the scientific literature now provides a variety of methodologies and numerical models with different degrees of complexity (e.g. one-dimensional, 1D, two-dimensional, 2D, and three-dimensional models, 3D) that play a key role in flood risk assessment. The potential of these numerical tools is enhanced by the amount of detailed data ensured by the advances of terrestrial and remote survey techniques (e.g. Schumann et al. 2009, Hall et al. 2011, and references therein), which provide modellers with highresolution topographic data (e.g. LiDAR), aerial and satellite imagery of flood events and water surface elevation data (ERS-2, ENVISAT; Bercher and Kosuth 2012, Tarpanelli et al. 2013). In this context, the availability of powerful flow routing models and detailed data may deceive modellers and practitioners into reproducing flood maps with the same resolution and accuracy as those of the data used for running the hydraulic model. However, as Dottori et al. (2013) point out, high spatial resolution models can increase the spreading of errors that affect topographical or hydraulic data (e.g. Di Baldassarre and Montanari 2009, Domeneghetti et al. 2012), while some physical processes, which are typically negligible for large-scale applications, may assume a relevant role in more detailed analyses. In these circumstances the choice of the appropriate numerical model and the correct implementation of the resolution mesh represent key aspects for the overall reliability of the flood hazard evaluation process.

Regarding flood analysis in lowland areas, it appears evident that inundation patterns are influenced by the presence of obstacles and civil structures, such as road embankments, levees or detention areas, which must be included in the hydraulic model. Analogously, the presence of a complex minor drainage network made of minor dikes and channels, pumping stations and other hydraulic infrastructures, may influence the flood evolution, conveying flows in areas which would have not been directly involved by the flood. Although these elements could be neglected in a largescale analysis, detailed analysis often neglects the effects of minor drainage networks. Hailemariam et al. (2013) represents one of the few analyses carried out in this field, while in many other cases, 
even if the resolution of topographic data (e.g. LiDAR data with a spatial resolution of $1 \mathrm{~m}$ ) enables the possibility of reproducing channels and other hydraulic structures, the drainage network is completely neglected, or modelled in a simplified manner, without considering its possibility for conveying water during the flood and draining the flooded area in the post-event period. These simplifications significantly influence the duration of flooding, which is one of the main variables that defines the amount of flood damages in agricultural areas (Citeau 2003).

This analysis refers to a specific case study along the Enza River, and investigates the effect of the minor drainage system on flood hazard estimation in the case of a dike breach. The evaluation is carried out by means of numerical simulations using a full 2D hydraulic model which refers to different meshes where the minor drainage network is modelled through different degrees of complexity.

\section{STUDY AREA, AVAILABLE DATA AND HYDRAULIC MODEL SCHEMATIZATIONS}

\section{Study area}

The study area is represented by the lowland rural area situated on the right side of the River Enza, close to Sorbolo a Levante, about $500 \mathrm{~m}$ from the right embankment of the river (Fig. 1). In this area, the backwater effect induced by the road and railway bridge strongly reduces the river freeboard, thus increasing the risk of overflow and consequent dike collapse. In 2013, the Regional Civil Protection Agency (RCPA) commissioned an investigation of the flood risk in case of a dike failure, providing a first delineation of the floodable area. Starting from the outcomes of this preliminary study, the present analysis further investigates the effects of the minor drainage network on flood hazard mapping. The study is carried out through the implementation of a cascade of two different numerical models. The first is a quasi-two-dimensional (quasi-2D) hydraulic model (Barkau 1997) for the simulation of the dike breach along the River Enza, whereas the second is based on a full 2D hydraulic model (Telemac-2D; Hervouet et al. 1994) for the simulation of flood dynamics. The topographic analysis of the study area was performed in a GIS environment, integrating the airborne LiDAR digital terrain model (DTM, available for the whole area at a resolution of $1 \mathrm{~m}$ ) with spatial information about the presence of civil infrastructures (e.g. main roads, railways, urban settlement, etc.) and drainage network (see. Fig. 1). The study area was identified in relation to the topographic elements that delimit the floodable area and has an overall extension of about $23.5 \mathrm{~km}^{2}$.

\section{Quasi-2D hydraulic model for River Enza}

The hydraulic analysis of the River Enza is carried out by means of a quasi-2D hydraulic model (see e.g. Castellarin et al. 2011) implemented for a 39-km river stretch from Montecchio Emilia to the confluence with the River Po. Referring to previous hydrological analysis carried out by the Po River Basin Authority (AdB-Po 2001), the quasi-2D model is used for the simulation of the 200-year return period flood event. Given the amount of uncertainty on physical and geometrical processes that generally characterize a dike failure (e.g. time of initial failure $(t)$, breach development time $(\mathrm{dt})$, and breach final width (w); see also Wahl 2001, Domeneghetti et al. 2013), the evaluation of the flood event is carried out by means of a Monte Carlo approach: the analysis considers 50 different breach scenarios defined by geometric parameters (i.e. $\mathrm{t}, \mathrm{dt}$ and $\mathrm{w}$ ) randomly sampled from ranges identified according to historical data available for neighbouring sites (i.e. Po River, see also Govi and Turitto 2000, and RCPA 2013, for more details). The breach configuration adopted as the reference event for the flood hazard evaluation is the one associated with the median overflow volume (total volume of about $21 \mathrm{Mm}^{3}$ ).

\section{D model implementation}

Flood dynamics in the lowland area are simulated using a 2D-finite element model (Telemac-2D, Hervouet et al. 1994). This model solves, through an overall limited computational cost, the 

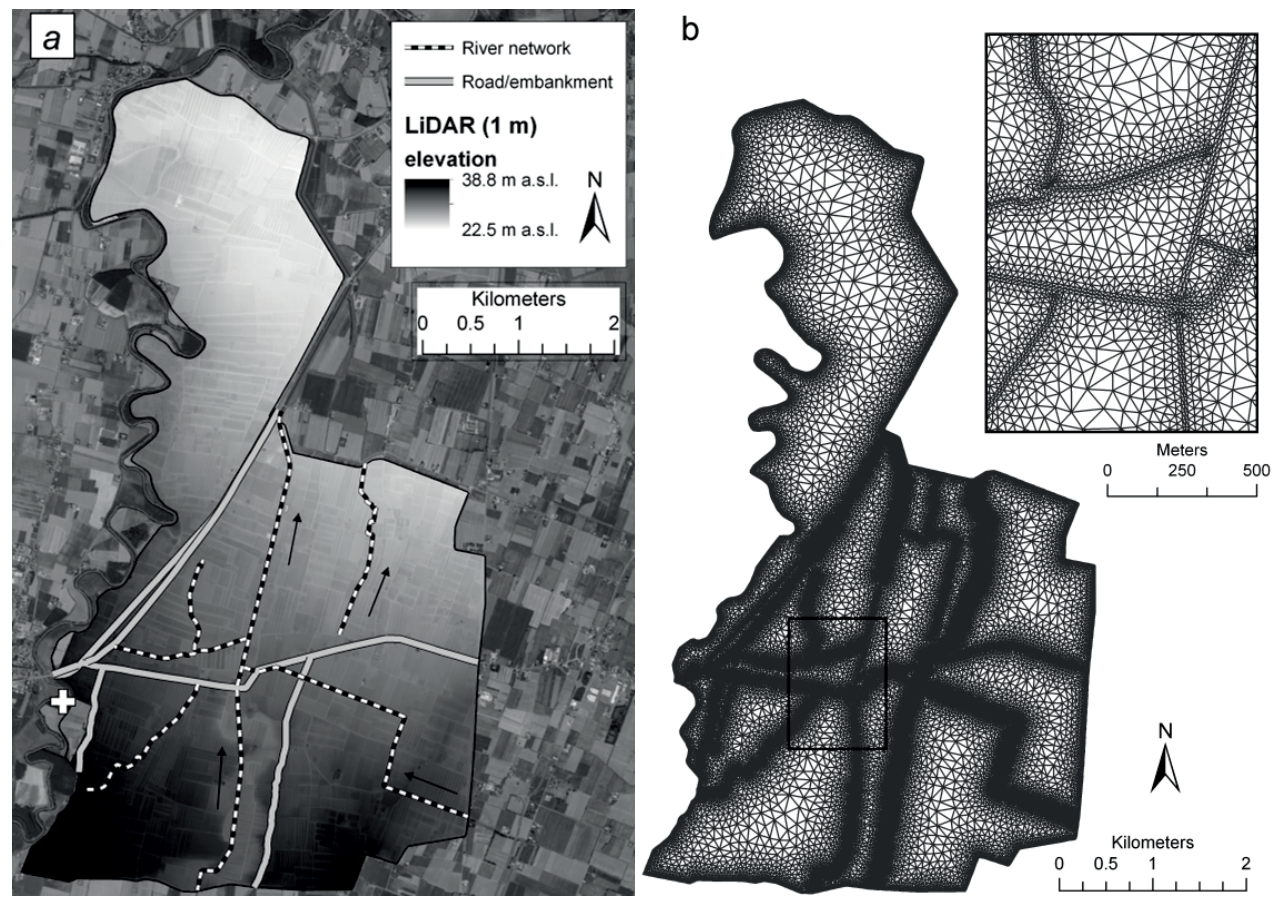

Fig. 1 (a) Digital elevation model (LiDAR) of the study area with main roads and the minor river networks of the flood-prone area; the white cross identifies the location of the breach failure. (b) Unstructured mesh adopted as reference configuration (i.e. REF) for the $2 \mathrm{D}$ model; insert, the representation of roads and channels in the numerical model by means of small triangular elements.

shallow water equations over an unstructured mesh describing the topographic discontinuities that interfere with the inundation process (e.g. embankments, roads, railway, etc.). The effect of the drainage network on the overland flow is simulated by considering three different unstructured meshes, hereinafter referred to as:

(i) REF (i.e. reference mesh): unstructured mesh of 26687 nodes and 51837 elements (distance from consecutive nodes ranges from $1.5 \mathrm{~m}$ to $150 \mathrm{~m}$ ). In this configuration the model considers the presence of the minor drainage network that can convey the water outside the study area and drain the flooded area (Fig. 1(b)).

(ii) REF-noFlow (i.e. the reference mesh without hydrodynamic flow): it uses the same mesh as REF but the drainage network does not drain the study area. The effect of the drainage network is considered only in terms of topographic obstacles or prevalent flow paths.

(iii) REF-noDN (no drainage network): the unstructured mesh, made of 14877 nodes and 28032 elements, only considers topographic discontinuities that rise above the ground surface for at least $50 \mathrm{~cm}$, and the drainage network is completely neglected (Fig. 2(a)).

The Manning coefficients adopted for all simulations are standard values (e.g. Chow 1959) selected as representative of the physical characteristics of the flood-prone area, distinguishing between different land-use type (roads, agricultural areas, minor networks, etc.).

\section{Schematization of the minor drainage network}

The minor drainage network is a complex system of small ditches and larger channels (width ranging from a few metres to $20 \mathrm{~m}$ ) that drain water from low-lying land, alongside roadways or fields, and bring water to a major river or to a pump station. The main drainage channels in the area of interest are highlighted in Fig. 1: Fig. 1(a) shows the scheme of the simulated drainage network and Fig. 1 (b) the reference mesh (REF) adopted in the 2D model. A system of channels flowing northward (see arrows in Fig. 1(a)) drains the water from low-lying areas, towards the Enza River. To ensure gravity-driven water flow to the Enza River, some channel stretches in the northern part of the network are embanked (Fig. 1(a)), thus preventing the possibility of flooding in the surrounding 
area. The hydraulic behaviour of the drain geometry was previously investigated by means of a simplified 1D model. Information retrieved from this preliminary investigation are used in the REF configuration to set up the initial and boundary conditions of the drainage network. Therefore, the 2D simulation starts considering a water depth elevation corresponding to a partial filling of the drain ditches, while during the flood event, the water surface elevation along embanked channels is limited to the maximum elevation of the corresponding embankment to avoid overflow from the network.

\section{RESULTS OF NUMERICAL SIMULATIONS AND DISCUSSION}

Figure 2(b) reports the maximum inundation extent (about $132 \mathrm{~km}^{2}$ ) and the maximum water depths simulated in the area of interest with the REF configuration. Table 1 summarizes the results for all the considered configurations, reporting the extent of flooded area, the maximum water depth and the maximum flooded volume. Concerning the maximum flood extent, the differences between the various configurations are relatively limited (Table 1). In particular, assuming REF as the reference scenario, both REF-noFlow and REF-noDN show a slight increase of floodable area with differences smaller than $10 \%$. This result is not surprising. In fact, if the flood-prone area is delimited by embankments and obstacles, the reproduction of the maximum inundation extent is an easy task, even referring to simplified models (see e.g. Hailemariam et al. 2013) and it does not represent the best benchmark variable for the evaluation of different model schematizations. Similar considerations can be also made for the maximum water depth, for which different configurations reproduce similar values. These outcomes could be expected as the flood dynamics appear to be strongly influenced by the prevailing slope of the area, with high water levels reproduced in the northwest of the study area.
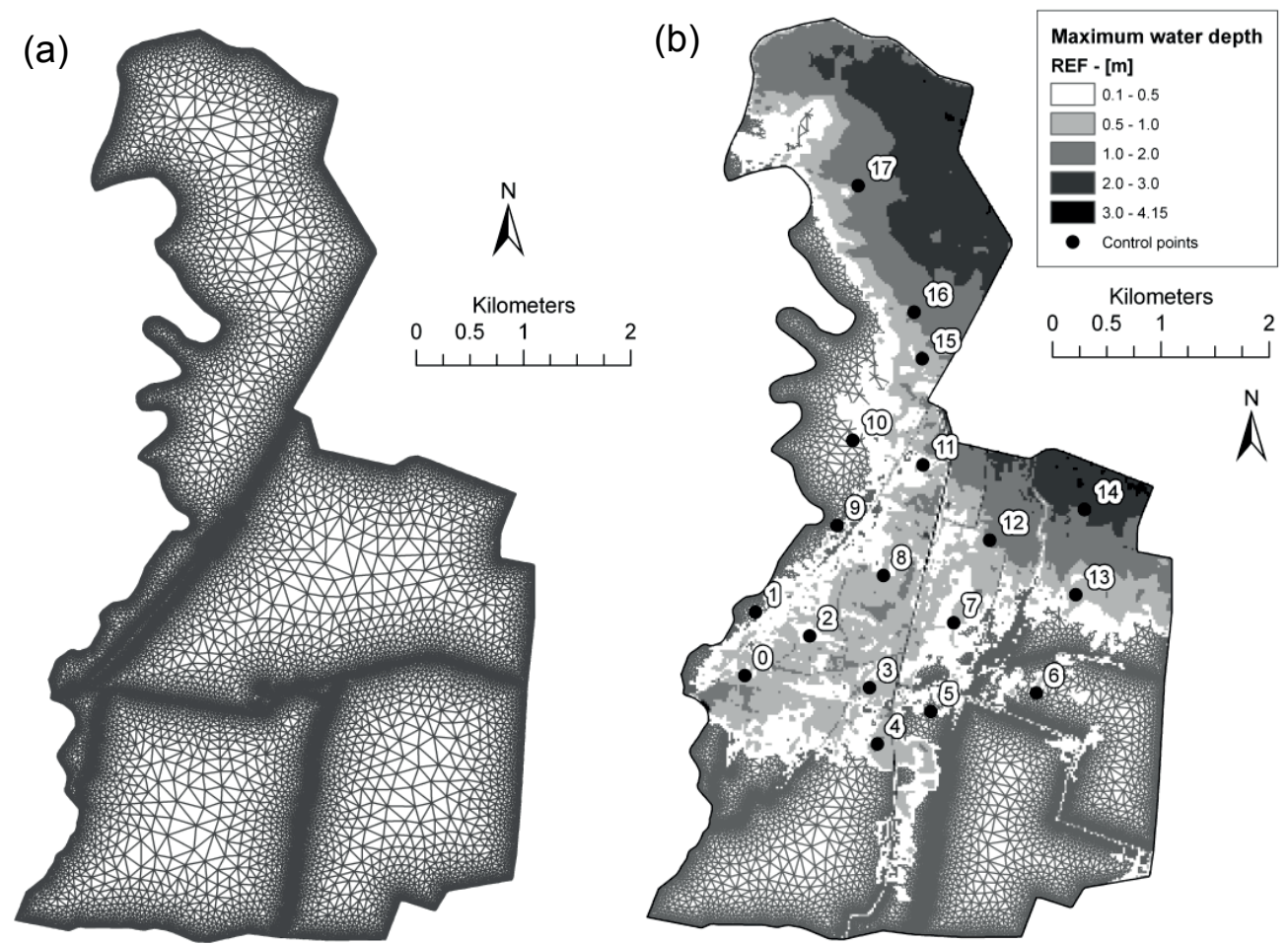

Fig. 2 (a) REF-noDN unstructured mesh. (b) Maximum water depths simulated in the study area adopting the REF configuration and control points (black dots) used for model comparisons.

Table 1 Results of 2D simulations performed with different model schematizations.

\begin{tabular}{llll}
\hline Mesh configuration & Flood extension $\left(\mathrm{km}^{2}\right)$ & Maximum water depth $(\mathrm{m})$ & Volume $\left(\mathrm{Mm}^{3}\right)$ \\
\hline REF & 132 & 4.15 & $\sim 10$ \\
REF-noFlow & 143.5 & 4.65 & $\sim 21$
\end{tabular}


Table 1 also reports the maximum water volume flooded in the study area highlighting a strong difference between REF and the other two configurations (REF-noFlow and REF-noDN). Figure 3(a) clearly highlights this aspect showing the temporal evolution of the water volume in the floodprone area during the whole simulation period. As expected, the drainage network conveys the water outside the flooded area by draining more than half of the total overflow (see REF).
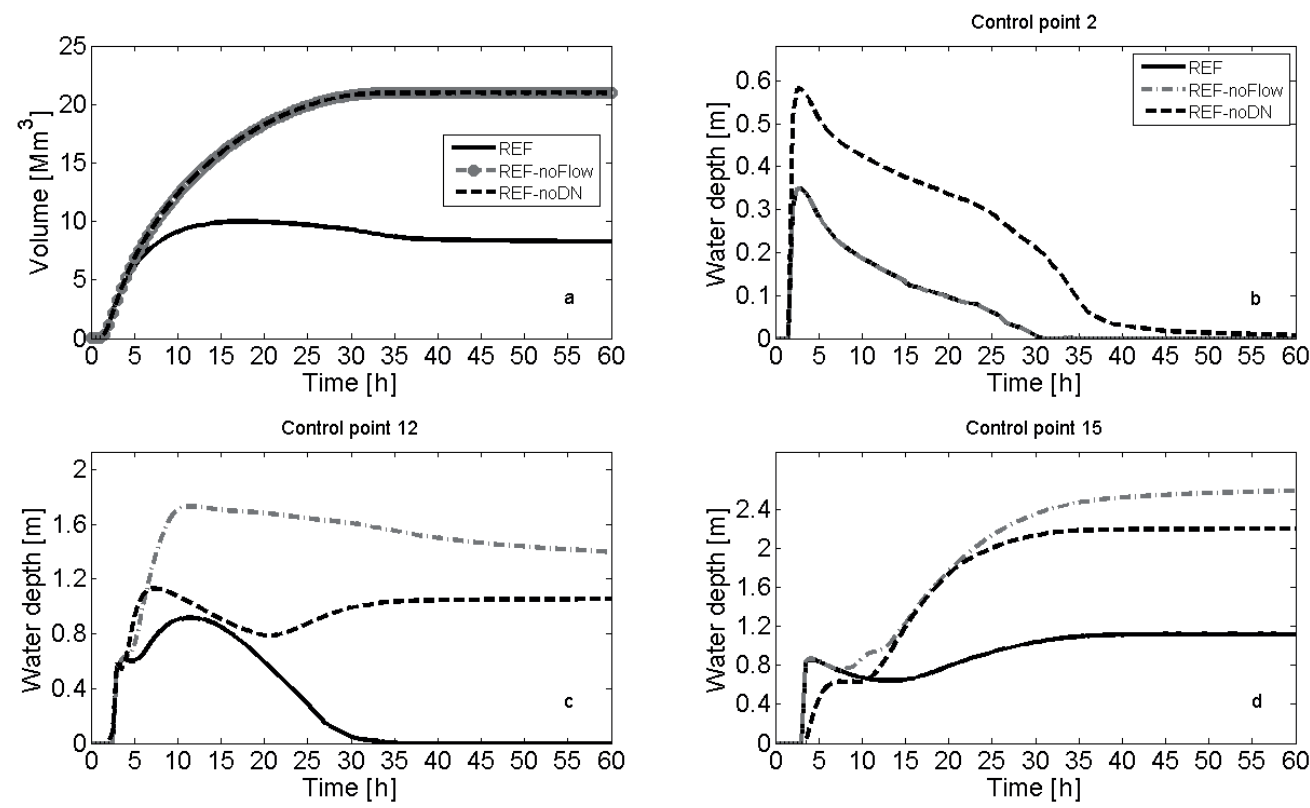

Fig. 3 Panel a: time evolution of the overall flooded volume in the study area. Panels b, c, d: water depth evolution for different configurations at checkpoints number 2, 12 and 15, respectively (see also Fig. 2b).

Figure 3(b)-(d) reports the temporal evolution of water depth at some of the numerous control points used in the present analysis (i.e. points 2, 12 and 15, respectively; see Fig. 2). Looking at point 2 (Fig. 3(b)), water depths for REF and REF-noFlow are similar, while higher values are obtained in the absence of the minor drainage network (i.e. REF-noDN). Considering the location of point 2 (Fig. 2(b)) this result seems clearly related to the presence of the drain network that conveys part of the water in different zones of the study area. During the simulation, it seems minor channels and ditches act as preferential flow paths, and convey water outside the study area (i.e REF) or in low-lying land (i.e. REF-noFlow). This latter hypothesis is highlighted in the evolution of water depths at points 12 and 15 (Fig. 3(c),(d)). In this case, if the drainage network is considered only in terms of flow paths without taking into account the possibility of draining part of the water outside the area (i.e. REF-noFlow) we introduce the risk of significantly overestimating the water depth in the low-lying part of the study area. It is interesting to note that errors reproduced in this part of the area in the configuration REF-noFlow are greater than those observed with configuration REF-noDN, for which the drainage network is completely neglected.

\section{CONCLUSIONS}

The main focus of the analysis is the investigation of the effects of the minor drainage network on the evaluation of flood hazard in the case of a failure of the main embankment system. Referring to a specific case study (Enza River; see Fig. 1), the study reproduces flood dynamics in the floodprone area by means of full 2D models, in which the minor drainage network is modelled with different degrees of complexity (i.e. REF, REF-noFlow and REF-noDN). The results clearly highlight the importance of the drainage network, which should be considered in the numerical model not just in terms of embanked channels or obstacles, but rather as preferential flow paths which may drain the flood-prone area and convey the water in the low-lying zones. Even if the 
maximum flood extent seems to not be particularly influenced by the presence of the drainage network, its presence strongly influences the water depth in many parts of the study area. Although this analysis does not provide general conclusions, it clearly emphasizes the importance of the minor drainage network. In fact, though not considered in much flood hazard analysis, the drainage network should be taken into account, especially when the duration of the inundation represents a key variable for a correct evaluation of the flood hazard and flood risk (i.e. agricultural damages). In these cases, a proper analysis of the overall system of minor ditches and channels appears fundamental.

\section{REFERENCES}

AdB-Po (2001) Piano stralcio per l'Assetto Idrogeologico (PAI). Interveti sulla rete idrografica e sui versanti. Po River Basin Authority, Parma.

Barkau, R. L. (1997) UNET One dimensional Unsteady Flow through a full network of open channels user's manual. US Army Corps of Engineering, Hydrologic Engineering Center, Davis.

Bercher, N. and Kosuth, P. (2012) Monitoring river water levels from space: quality assessment of 20 years of satellite altimetry data. In: 20 Years of Progress in Radar Altimetry (24-29 September 2012), 2-7, Venice.

Castellarin, A., Domeneghetti, A. and Brath, A. (2011) Identifying robust large-scale flood risk mitigation strategies: A quasi-2D hydraulic model as a tool for the Po River. Physics and Chemistry of the Earth, Parts A/B/C, 36(7-8), 299-308. doi:10.1016/j.pce.2011.02.008.

Chow, V. T. (1959) Open-Channel Hydraulics. New York, US: McGraw-Hill.

Citeau, J. M. (2003) A new control concept in the Oise catchment area: definition and assessment of flood compatible agricultural activities. FIG working week, Paris, France.

Di Baldassarre, G. and Montanari, A. (2009) Uncertainty in river discharge observations: a quantitative analysis. Hydrol. Earth Syst. Sci., 13, 913-921, doi:10.5194/hess-13-913-2009.

Domeneghetti, A., Castellarin, A., and Brath, A. (2012) Assessing rating-curve uncertainty and its effects on hydraulic model calibration. Hydrology and Earth System Sciences, 16(4), 1191-1202. doi:10.5194/hess-16-1191-2012.

Domeneghetti, A., et al. (2013) Probabilistic flood hazard mapping: effects of uncertain boundary conditions. Hydrology and Earth System Sciences, 17(8), 3127-3140. doi:10.5194/hess-17-3127-2013.

Dottori, F., Di Baldassarre, G., and Todini, E. (2013) Detailed data is welcome, but with a pinch of salt: Accuracy, precision, and uncertainty in flood inundation modeling. Water Resources Research, 49(9), 6079-6085. doi:10.1002/wrcr.20406.

EC European Parliament Council (2007) Directive 2007/60/EC on the Assessment and Management of Flood Risks, 23 October 2007, http://eur-lex.europa.eu/en/index.htm.

EM-DAT (2011) OFDA/CRED International Disaster Database, Universite Catholique de Louvain, Brussels, http://www.cred.be/emdat.

Govi, M. and Turitto, O. (2000) Casistica storica sui processi d'iterazione delle correnti di piena del Po con arginature e con elementi morfotopografici del territorio adiacente (in Italian), Istituto Lombardo Accademia di Scienza e Lettere.

Hailemariam, F. M., Brandimarte, L., and Dottori, F. (2013) Investigating the influence of minor hydraulic structures on modeling flood events in lowland areas. Hydrol. Process. (in press). doi: 10.1002/hyp.9717.

Hall, A. C., et al. (2011) Tracking water level changes of the Amazon Basin with active space-borne remote sensing and integration with large scale hydrodynamic modelling: a review. Physics and Chemistry of the Earth, 36, 223-231.

Hervouet, J. M., et al. (1994) The computation of free surface flows with TELEMAC. An example of evolution towards hydroinformatics. Journal of Hydraulic Research 32, 45-64.

RCPA-DICAM (2013) Individuazione di misure di mitigazione del rischio idraulico e predisposizione di metodologie speditive per la previsione quantitativa dei danni da inondazioni fluviali (in Italian), Research agreement between the Regional Civil Protection Agency of Emila-Romagna and DICAM Department, November 2013, Bologna.

Schumann, G., et al. (2009) Progress in integration of remote sensing-derived flood extent and stage data and hydraulic models, Rev. Geophys., 47, RG4001, doi:10.1029/2008RG000274.

Tarpanelli, A., et al. (2013) River discharge estimation by using altimetry data and simplified flood Routing modeling. Remote Sensing, 5, 4145-4162. doi:10.3390/rs5094145.

Wahl, T. L. (2001) The uncertainty of embankment dam breach parameter predictions based on dam failure case studies. In: USDA/FEMA Workshop on Issues, Resolutions, and Research Needs Related to Dam Failure Analysis, 1-16, 26-28 June, 2001, Oklahoma City, USA. 